Original Research

\title{
Exploring the Elderly Care System: A View from Community in Thailand
}

\section{Amaraporn Puraya, Duangporn Piyakong, Sugritta Wongwiggan and Roongtiva Boonpracom}

Faculty of Nursing, Naresuan University, Phitsanulok, Thailand

\begin{abstract}
Introduction: Thai society is becoming an aging society due to the increase of the population aged 60 years or above. Developing the elderly care system in the community is important and needs cooperation from many sectors in order to provide care for the elderly effectively. The objective of this research was to explore the meanings of the elderly care system in community in Thailand, using a qualitative research approach.
\end{abstract}

Methods: This descriptive qualitative research design was conducted with 40 informants at a community in a province located at the lower northern region of Thailand. The informants were divided into two groups. 1) The main informants were the Chief Executive of the Local Administrative Organization (LAO). 2) The secondary informants were those who had been guided to help the elderly in the community and family. The data were collected by observation, in-depth interviews, focus group discussions and document study. The reliability of the data was verified by triangulation. The data were analyzed by content analysis.

Results: The results of the meanings of the elderly care system in community was defined as five themes: providing help and support, having networks, volunteerism, having knowledge and knowledge management, and community solidarity.

Conclusion: The elderly care system in the community is in line with the participation process of all parties, both inside and outside the area, to jointly conduct activities to deal with problems and develop various operations in the area to support the elderly care system in the community.

\section{ARTICLE HISTORY}

Received: January 21, 2021

Accepted: April 26, 2021

\section{KEYWORDS}

the elderly; the elderly care system; thailand

\section{CONTACT}

\section{Amaraporn Puraya}

$\bowtie$ ning20047@gmail.com

$\equiv$ Faculty of Nursing, Naresuan University, Phitsanulok, Thailand

Cite this as: Puraya, A., Piyakong, D., Wongwiggan, S., \& Boonpracom, R. (2021). Exploring The Elderly Care System: A View from Community in Thailand. Jurnal Ners, 16(1). 89-95. doi:http://dx.doi.org/10.20473/jn.v16i1.24918

\section{INTRODUCTION}

The rapid change in population structure around the world has resulted in the increase of the population aged 60 years and over, both in number and proportion to the total population, while the population of children continues to decline (Srithamrongsawat et al., 2015). It is reported that, by 2050 , the number of the elderly will increase to 1,963 million people, accounting for $22 \%$ of the total population (Sorakrij, 2016). This is another wave of social change that will cause a greater proportion and number of older people than the younger population (0-14 years) when compared to the proportion of the elderly per total population in 2050 (Opasanant, 2017). Thailand had approximately 5.5 million older people (8\%) in 2015 and it will increase to 22 million people $(27 \%)$ in 2050 (Bureau of Policy and Strategy, Health Ministry of Public Health, Thailand, 2011).

According to the situation of the aging population in the past 10 years in Thailand, the number and the proportion of the population aged 60 years and over increased to $9.2 \%$ in 2000 . In 2019, the proportion increased to $17.36 \%$ (Ministry of Public Health, Thailand, 2020). This indicates that Thai society is entering an aging society. Developing the elderly care system in the community is important and needs cooperation from many sectors to effectively drive the implementation. Therefore, it is necessary to develop community potential in providing care for the elderly in every aspect, such as policy, mechanism and management. Moreover, the coordination 
mechanism at provincial, district or sub-district level must be enhanced (Vattanaamorn, 2012). Healthcare providers at Tambon Health Promoting Hospitals, the first level of public health service system in Thailand, and village health volunteers in the community must be the leaders or a key person in management and provision of healthcare services for the elderly. Organizations in a community and local administrative organizations (LAO) have to provide support to elderly people in the community (Nuntaboot, 2013a; Phinyoo, 2013; Poonthawe, 2017). The operation needs cooperation from local government organizations, health service units, elderly groups and related mechanisms in order to be an effective community center in caring for the elderly. This is also a way to promote and support families, community organizations, as well as the volunteers who care for the elderly in the community through three important strategies, as follows: 1) encouraging the elderly to live without dependence; 2) focusing on disease prevention strategies and appropriate health promotion; and 3) promoting the elderly to have healthy physical and psychological conditions. Therefore, elderly people in a community must be developed and promoted so that they have quality of life and are able to adapt to any changes effectively. Knowledge and experiences of the elderly should be used and preserved as the national treasury to benefit society and the nation. Also, the population of all ages and groups must be prepared to enter the aging society appropriately. The social systems and mechanisms that support people in society to live with stability, happiness and good quality of life must also be created. (National Research Council of Thailand, 2014; National Seniors Council, Aging Funds, Foundation of Thai Gerontology Research and Development Institute; 2012)

The elderly care system in the community makes Thai people in such community continuously increase potential and strength in supporting each other (Nuntaboot , 2010). It is one of factors that are important to wellbeing of the elderly living in the community. Elderly care systems in Thailand have been developed over a long period of time through legislation, regulations, policies, strategies and projects as the national and local level., so that the elderly can be strengthened and live happily in the society (Nuntaboot 2016). This reflects the care of the elderly connected with the socio-cultural context. In addition, different care potential of the relevant organizations may affect the care system for the elderly in different ways. Therefore, the existing elderly care knowledge of each community does not respond to the problems and the needs of the elderly when the situations and the socio-cultural context change (Nuntaboot, 2016; Phinyoo, 2013; Poonthawe, 2017).

Phetchabun Province, a province in the lower northern region of Thailand, is one of the provinces having many elderly persons. Moreover, the proportion of elderly population has increased rapidly. In addition, the elderly care in this province has been provided by the main organizations in this area, such as family and elderly groups, local government organizations, and healthcare organizations due to recognizing problems and the real needs of the elderly. For this reason, the elderly care system in a sub-district community should respond to problems and needs of the elderly in order to help them live in the family and the community for a long period of time with a good quality of life. The researchers believe in the potential of individuals, groups, and community organizations taking part in elderly healthcare with different care needs, leading to the synthesis to learn about the elderly care system in the community and the health of the elderly according to the socio-cultural context of the area (Opasanant, 2017; Poonthawe, 2017). Therefore, the researchers would like to explore the meaning of the elderly care system in this community from various key informants.

\section{MATERIALS AND METHODS}

This was descriptive qualitative research studying a sub-district in Petchaboon Province which is located at the lower northern region of Thailand. This subdistrict comprises of nine villages. The data collection was carried out from December 2019 to April 2020. The informants were selected by a purposive sampling method. The informants were 40 people in total, divided into two groups. 1) The main informants were the Chief Executive of the LAO, LAO officers, a principal and teachers of the Elderly School, a registered nurse, public health officers from the Tambon Health Promoting Hospital, community leaders, elderly care volunteers or the village health volunteers, the representative from the elderly club, the strong community leaders, the leaders of social groups, and occupational groups. 2) The secondary informants were those who had been guided to help the elderly, the social group members who had gained assistance, caregivers who were the family members of the elderly, the elderly who received care and the supporters for potential performance such as the staff of Tambon Administrative Organization and the Elderly School.

Data collection was performed by (1) participant observation and non-participant observation by observing the community activities, including physical characteristics, activities, community events, and gathering of people involved in the elderly care; (2) in-depth interviews; (3) focus group discussions with the local leaders, the leaders of community organizations and the volunteers in order to review the information on work and activities involved in caring for the elderly; and (4) documents by studying the available information under the community actions, including population data, civil registration, Thailand community network appraisal program (TCNAP), the reports of Rapid Ethnographic Community Assessment Process (RECAP) and other information available in the community, such as basic necessity information, basic information at the village 
level, the information of subsistence allowance, the information of the needy in need of assistance and the health information from the Tambon Health Promoting Hospital.

Data analysis was performed by organizing data, finding out meaning and classifying the components and investigating the relationships of data, leading to the generation of a conclusion that illustrates the findings of this research. This was done through content analysis, typological analysis, matrix tables, rigor and trustworthiness (Phothisita, 2011). Triangulation was employed. The results of the analysis were checked with the key informants, the local government organizations and the health service unit administrators, who knew well about the phenomena in the area of study. This study was certified by the Ethics Committee on Human Research, Naresuan University, IRB Number 0981-62.

\section{RESULTS}

The results of reflecting the meanings of the elderly care system in community were interpreted as five themes: help and support, having networks, volunteerism, having knowledge and knowledge management, and community solidarity.

\section{Help and support}

In the theme of help and support, the informants conceived the development process of the elderly care system of the sub-district and networks of local government organizations where they live and caused the knowledge in reflecting the selfmanagement of local communities. It was the comprehensive support for social, economic, environmental and health aspects of each area. Moreover, the body of knowledge, including the new knowledge and the knowledge from practice and academic confirmation, was examined by the community. Informants agreed that they are good for elderly care management, which can be developed into a public policy proposal with confirmation from RECAP and TCNAP. There was also the body of knowledge on the basis of helping each other by collecting various knowledge in a systematic manner and disseminating it to the community. In addition, there was the development process to create benefits for self-reliance and support. Some informants stated:

"In terms of kindness and assistance, we help each other in our sub-district. For example, when nurses have to organize activities for the elderly at the elderly school, they will ask for help from the elderly. All of the elderly help out. This is just one example of the assistance of the elderly in our subdistrict." The Chief Executive of the LAO

"At our village, our relationships are like siblings. We have known each other from parents' generation. We take care of each other like relatives. We know everyone in the village. We help and take care of each other." The village headman

"There are a lot of good and talented people in our community. We need to bring them together to find out the problems and needs and to support the implementation of comprehensive care practices for the elderly in the community and to provide cooperation, help and support each other." The staff of the LAO

"Normally, I do farming. I rarely take care of myself. I have diabetes and high pressure. When I go to the Elderly School, the teachers teach me to take care of myself and other elderly people in the family. I am now taking more care of my health and other elderly people in my family." An elderly person "At auntie Phon's house, her mother is sick and stays underneath the house. Other elderly people who do not go out to work in the rice fields usually visit and take care of auntie Phon's mother. They take care of and help each other like they are relatives" Village health volunteer

\section{Having social networks}

Informants expressed that the elderly care system was a model in using the existing potential in the community and social capital to solve problems, which could truly meet the needs of the elderly in their community. The informants also explained that a lot of social networks of the elderly care system could be built from the care of multidisciplinary team and local government organizations. The networks of local administrative organizations create livable local communities. The system implementation, the management structure and the curriculum structure for opening the Elderly School have been supported. The speakers gave knowledge about the establishment of the Elderly School to many agencies outside the network. The Elderly School was an example of the community elderly care system in building social networks. Some informants expressed as follows:

"I will ask good and talented people who understand the problems to help find out the problems, such as the problem of the increasing number of the elderly. I want to support the comprehensive elderly care approaches to be the practices of our sub-district. I want everyone to help each other to and build an elderly care network together because in the future we must be old." The Chief Executive of the LAO

"We ask for cooperation from local organizations and other organizations having knowledge and experiences in the elderly issues outside the area in order to develop our community and create cooperation. We have different expertise, so we should help develop our sub-district to be the network together." The Principal of the Elderly School

"I am glad that other people visit to see our Elderly School in the sub-district. We can exchange knowledge. Sometimes, the Chief Executive of the LAO takes us to learn from other schools in the network. So, the obtained information can be used for development, making our sub-district strong. 
The key is to have friends and networks." An elderly person

\section{Volunteerism}

This theme can be divided into three sub-themes. 1) Having positions or roles: This sub-theme refers to the persons with the volunteer positions, appointed by the government agencies, sub-district administrative organization or non-profit private organizations, including village health volunteers, elderly care volunteers, disabled care volunteers and Civil Defense Volunteers. 2) Having volunteer spirit: This refers to those who do things with volunteer or public spirit that will benefit the elderly in the area. These volunteers want to help others to overcome their illnesses and alleviate their suffering. 3) Having opportunities or readiness: This refers to those who have knowledge, skills, and expertise. These people usually give assistance when having opportunities, such as when they are invited by friends and they realize that they are necessary and have specific knowledge and experience in that subject and are ready to work. The informants reported as follows:

"...In the past, I was a normal elderly person, helping the community. During that time, the headman in the area asked the elderly to be the volunteers. Later in 1992, I was trained as a volunteer and was the president of the village health volunteer. In 1995, I was elected by a meeting to be the president of the village health volunteer at the sub-district level. Until now, it is more than 30 years." The president of the village health volunteers

"...I am a village health volunteer because I want to help the community, and have knowledge and experience and use the knowledge to help and take care of myself and my family. I also want the community to be a better health community in all aspects." Village health volunteer

"...We try to look at problems and related matters to find out the information and think about how we can respond to them. In this year, in terms of the elderly issues, we have thought about doing some activities with the elderly. We also have prepared the information of the elderly in the subdistrict. We care for all of the elderly in the subdistrict. Also, we have searched for disadvantaged elderly people to help." The staff of the LAO

"....After receiving a phone call from the villagers informing that there was heavy rain and it was flooded, I called to ask for coordination from civil defense volunteers. I also called PAO to ask for equipment support such as sandbags. We helped each other in dredging the canal. Many parties and organizations helped each other." The administrator of the LAO

"...After retirement, I saw other people in the community had already worked about funds and the Elderly Club ... My sister invited me to join the club, so I applied for the membership first ... I want to help the community and the elderly who are in trouble." An elderly person

\section{Having knowledge and knowledge management}

Research studies have been conducted to create new knowledge coupled with local wisdom. The local community researchers have been supported together with the researchers from educational institutions. Knowledge has been collected in a systematic manner and disseminated to the community. Some informants stated:

"To show that our sub-district has a good elderly care system, we, as a volunteer, must have knowledge about care. Nowadays, there is a lot of knowledge in the internet. But most importantly, we need to have correct knowledge in order to be able to take care of elderly people in our sub-district. We also need to develop our own potential on a regular basis." Village health volunteer

"Local wisdom is the creation of experience until it is crystallized and can be transmitted from generation to generation, representing the knowledge of the people in the sub-district." The folk philosopher

"I am a retired government official. Then, I am a student at the Elderly School in order to develop myself. I help take care of other elderly people in the sub-district. If we have knowledge and potential, we can take care of other elderly people, and our subdistrict will have a good elderly care system." An elderly person

\section{Community solidarity}

Informants reflected about the integration of people in each village and between the villages. Occupation groups are formed, coexistence rules are established and community unity has been promoted. People in the community have participated in thinking, learning, and practicing together and there is a learning process. The informants expressed as follows:

"The people in the sub-district are supported and empowered. The power of the people in the sub-district is also built. If the villagers are happy, the leaders are also happy too. This is our strength. We have unity in the sub-district." The Chief Executive of the LAO

"Everyone in the sub-district usually helps each other doing activities. They feel like they are the owner of the sub-district. No matter what job or activities, everyone will help each other do them, including Subdistrict Administrative Organization, the village headmen, health centers, schools, temples, and villagers." The village headman

\section{DISCUSSION}

The results obtained in this study according to community contexts and situation showed that the elderly care system in a community form the informants' viewpoint as (1) providing help and support, (2) having networks, (3) volunteerism, (4) 
having knowledge and knowledge management, and (5) community solidarity.

The results of this study reflected the meaning of the elderly care system in terms of help and support as the first theme. It may be possible that the elderly care system of this area obviously received help and support through community participation, collaboration and agreement. The findings demonstrated that the process of elderly care system development by sub-district and local government organization networks was a crucial factor in community knowledge creation and transformation. This provided community in effective selfmanagement and problem solving in elderly care. It drove the accomplishment of elderly care to meet their own basic needs, covering social aspect, economic aspect, infrastructures and health maintenance. It had been previously documented that an elderly care system which was developed by community participation caused formal and informal social groups. These groups had a firm and strong connection with a helping hand within community members (Chankham et al., 2015).

Services and support from a community collaboration led to effective services for elderly revealed as the first theme. For example, 1) the elderly with chronic illness such as hypertension, diabetes or elderly with disability received home care from trained health personnel and the elderly were also informed and advised. 2) The community had a referral system for those who had acute condition. 3) The community also provided many funds to be economic welfare assistance for the elderly.

The second theme, having networks, is consistent with the concept of community participation and the concept of social capital. The elderly care system in this study used networks, which is social capital, to solve the problem, leading to meeting the true needs. This reflects the community power in the decisionmaking process and setting community mutual goals. (Vattanaamorn, 2012). Moreover, the elderly care system using networks are formed among community members and among villages. (Field, 2018).

Moreover, this community has a famous elderly school, Wang Tha Di Elderly School, as a key component of network development. This school has four networks and 10 elderly care system development networks, and 60 cross-local government organizations cooperation. Wang Ta Di Elderly School team was a mentor for creating 100 elderly schools across Thailand. Therefore, the informants of this study expressed one of the meanings of elderly care system as having networks

Another theme of the results of this study is volunteerism. The informants gave the meanings of volunteerism as formal or governance volunteerism, non-formal volunteerism, and social act or situational volunteerism. Formal or governance volunteerism is the practice from a volunteer who is the government or nongovernment officer, such as a village health volunteer, an elderly care volunteer, and a volunteer caring for people with disabilities. Informal volunteerism refers to the practice of a non-officer volunteer who provides their time and skills without pay to help the elderly suffering from illness or poverty and improving the elderly's basic quality of life (Wongprom, 2015). In this community, nonformal volunteers were the leaders or committees of various funds and welfares. Social act or situational volunteerism were the citizens who had special skills, folk philosophers, or pensioners who needed to participate in their society in a suitable situation. The result in this study is consistent with a study by Kraithaworn (2013) which examined predicting factors. The result revealed that working with local people who you have been familiar with for a long time can improve work efficiency.

The result showed another theme which was having knowledge and knowledge management. The possible reason of this finding might be because this community-based elderly care system generated several benefits associated with knowledge and knowledge management for elderly and younger citizens. The older people indicated that they had exchanged their own knowledge with other generations. Moreover, the elderly informants explained that the Elderly School was a place for lifelong learning for the elderly. They gained more knowledge about health, occupation, and economics, etc. from the school. Moreover, community groups and elderly clubs or occupational clubs was one of the knowledge transferring channels for the elderly. Many activities in elderly care systems were designed for knowledge exchange, such as group discussions between elder people, generations, the community, or discipline, occupation group and excursion. It was not only a place for knowledge transferring, but also a place for freely talking, informing of news and information, or expressing their problems (Srithamrongsawad, 2015). This elderly care system also had indirect results for the elderly's psychological health. The informants felt their selfesteem had been strengthened result from the community recognition and engaging in community opportunity. The elderly's mental health wellness had been raised from social recognition and social position. Some of them had been promoted to be a folk philosopher, a speaker, or a leader. An indigenous knowledge, experiences and folk wisdom, including tacit knowledge, are passed on from one generation to the next generation over decades (Sriphrom, 2013).

One possible explanation of the finding is that Wang Tha Di Sub-District Administrative Organization ameliorated the elderly care system through a knowledge management process. New strategies or technologies had been employed. The elderly care system had been developed through knowledge exchange and transfer. For instance, knowledge about physical therapy for the disability, daily foot checking in elderly with diabetes mellitus, disability care, elderly care, and care of the elderly with chronic disease were operated from caregivers to others through knowledge transfer. Another 
method about knowledge sharing employed by Wang Tha Di Sub-District Administrative Organization was research. Research project cooperation between the community organization and university lecturers was launched in order to discover new knowledge in elderly care.

The solidarity among community members and social group is a key of social development in Thai communities, as found as the last theme, particularly in rural areas. The relationship between family members is tight because most Thai families in rural areas are extended families. People in Thai communities are close to each other in various dimensions. It is a major fundamental factor for social welfare. According to the results, social integration via occupation groups, elderly school, and caregivers strengthens social solidarity. Elderly care systems could strengthen community solidarity through providing help and support, volunteering, networks, and community knowledge, in order to diminish elderly problems.

This corresponds to community management process, cooperative learning, and increase in social capital value, under the relationship between citizens and networks, both intra community and intercommunity. So, people must contribute in every process of social activities by using the community real database with the citizen power to develop or solve the community's problem (Phromsuan, 2018).

\section{CONCLUSION}

The elderly care systems in the community are in line with the participation process of all parties. It is a way of working that connects groups of related organizations in and outside the area to jointly do activities to deal with problems and develop various operations in the area by utilizing the potential from all parties that are the structures in the sub-district through the life scenarios in the community to support the elderly care system in the community in caring for the elderly in five themes, namely helping and supporting, volunteerism, having networks, having knowledge and knowledge management, and community solidarity. People are satisfied with the integrated work development approaches in developing the elderly care system in their community.

\section{ACKNOWLEDGMENT}

This research was conducted in the area of Wang Tha Di Sub-District Administrative Organization, Nong Phai District, Phetchabun Province. The researchers are grateful to the Chief Executive of Wang Tha Di Sub-district Administrative Organization, the administrators, the community leaders, the leaders of the community organization group, the volunteers and the administrators and the staff of Ban Klang Health Promoting Hospital for supporting and facilitating the data collection and research conduction. The researchers also would like to express gratitude to the Office of Community Health
(Bureau 3), Thai Health Promotion Foundation for supporting with the research fund.

\section{REFERENCES}

Bureau of Policy and Strategy, Health Ministry of Public Health, Thailand. (2018(. Health Annual Report 2018. Nonthaburi, Thailand: The War Veterans Organization of Thailand Under Royal Patronage of His Majesty the King. )in Thai(.

Field J, (2018). Social Capital. 4nd ed. New York: Routledge Taylor \& Francis,

Jaranya Wongprom et al. (2015). Community Participation in the development of Older Persons' Quality of Life. Veridian E-Journal, Slipakorn University. 8(3), $41-54$.

Kraithaworn P, Piaseu N, \& Noinam S. (2013). Factors predicting sense of community belonging. Journal of Public Health Nursing, 27 (1), 2-15.

Ministry of Public Health, Thailand. (2018(. Older person roles for social family and community. Retrieved from http://hp.anamai.moph.go.th/soongwai/statics/ab out/soongwai/

National Research Council of Thailand. )2016(. Exclusive summary of research strategy of older people and aging society, Year 2012-2016. Retrieved from http://nrct.go.th/ Portals/o/data/2557/RPP/strategy_sub/24-pdf

National Seniors Council, Aging Funds, Foundation of Thai Gerontology Research and Development Institute. (2012). Thailand Aging Situation Report of 2010. Bangkok, Thailand: Pongpanichchareanpon. )in Thai(

Nuntaboot, K. (2010). Community Health System: The Process of 3 main Systems in the community. Nonthaburi, Thailand: the Graphico System. )in Thai(

Nuntaboot, K. )2013a(. Rapid Ethnographic Community Assessment: RECAP. Bangkok, Thailand: Thai Health Promotion Foundation. )in Thai(

Nuntaboot, K. )2013b(. Summary report: The workshop of elderly health system development by area base. Khon Kaen, Thailand: Faculty of Nursing, Khon Kaen University.

Nuntaboot, K. )2016(. Strengthening local communities in the development of the community health care system and using the sub-district health funds as the support mechanism. Khon Kaen, Thailand: Faculty of Nursing, Khon Kaen University.

Nuntaboot, K. )2017(. Thailand Community Network Appraisal Program: TCNAP. Bangkok, Thailand: Thai Health Promotion Foundation. )in Thai(

Nuntaboot, K., Boonsawadkulchai, P., Piyabundikul, L., Jirraratanawana, N., Wathanaamorn, S., Chantharasiri, J., et al. )2010(. The Process of Community Research for Healthy Tambon. 3rd ed. )n.p.(: TQP. )in Thai( 
Opasanant, P. )2017(. Development of Health Service System for Older Adults in the Community. Journal of Nursing and Health Care, 35)2(, 177-187.

Panchan S.)2012(. Community Participation in the Process of Care of Elderly at MABCARE Subdistrict. Journal of The Royal Thai Army Nurses, 13)2(, 8-17.

Phinyoo, K. )2013(. Strengthening of the community voluntary system. Khon Kaen, Thailand: Khon Kaen University.

Phothisita, C. (2011). Science and arts of qualitative research, 4th ed. Bangkok, Thailand: Amarin Printing.

Prasartkul, P. )2013(. Aging Situation: Trends and Impacts of Accession to the ASEAN Community. Documentation for the ASEAN Community and Senior Societies conference at Miracle Grand Convention Hotel on 12 Dec 2013. Retrived , from http://hp.anamai.go.th/download/Meeting10_13 Dec.2556/12.Dec.2556/3.pdf )in Thai(

Prasartkul, P. (ed.). (2016). Situations of the Thai Elderly in 2016. Bangkok, Thailand: Printery.

Poonthawe, P. )2017(. Volunteering Spirit in Youth: A Community Developed Model. Journal of Nursing and Health Care, 35)4(, 42-51

Sorakrij, C. )2016(. Chronic Conditions Experiences: Meaning and Care Management. Journal of Nursing and Health Care, 34)1(, 65-72.
Sriphrom, S. (2013). Community Participation in Development of Long Term Elderly Care Model in Tambon Thad, Amphur Warinchamrab, Ubonrachathani Province. [thesis].

Srithamrongsawat, S., Bundhamcharoen, K., \& Amnatsatsu,e K.(2015). Community Care Model for Older People in Thailand. The Thai Journal of Primary Care and Family Medicine, 1(2), 22-31.

Vattanaamorn S. (2012). Community care system for the people who require assistance [dissertation]. Khon Kaen: Graduate School, Khon Kaen University.)in Thai)

Wariya C, Hathaichanok B, Chinnawut 0.)2558(. Elderly Care System Model by community and local government with self-management Case study : Targnam Sub-district local government, Inburee District, Singburee Province. Area Based Development Research Journal, 7(3), 22-41.

Woranart P ,)2018( . Strengthening of the community social capital for care of the aged. Journal of Nursing Science \& Health. 41 )2(, 90-98

World Health Organization. )2019(. World Health Statistics 2019. Retrieved from http:/www.who.int/gho/publications/world_healt h_statistics/EN_WHS2015_Full.pdf 